\title{
Antecedents and outcomes of destination image of Malaysia
}

\begin{abstract}
The main objective of this paper is to analyse the antecedents and outcomes of destination image. Specifically, the antecedents considered are cultural values and destination source credibility; the outcomes considered are destination attachment, destination satisfaction, and revisit intention. This paper also investigates the moderating role of perceived risk between destination image and revisit intention. A questionnaire-based survey was conducted on international tourists from five countries of West Asia. The key findings of this study are the mediating roles of destination image, destination attachment, and destination satisfaction and moderating role of perceived risk. The results provide evidence concerning the role of mediators and moderators of the study. Theoretical contributions are discussed, with future research suggested.
\end{abstract}

Keyword: Destination image; Cultural values; Destination source credibility; Destination attachment; Perceived risk; Malaysia 